the cubicle in which the subjects were confined was lighted but rendered semi-soundproof: at Princeton the room was lightproof and soundproof.

Examination of the effects of sensory deprivation was originally intended to throw light on the reduction of variability and quantity of sensory stimuli as a potential hazard in space flight, but even before these experiments unusual sensory effects had been recorded with radar observers and other workers engaged in very monotonous and routine jobs. As observations multiplied, so the whole subject became connected with what was called 'brain. washing' and this was the main point dealt with by the experiments at McGill.

Dr. Vernon's arrangements were more severe than those of Dr. Hebb, although both used only male subjects, those assisting Vernon being about one hundred Princeton graduates aged between twenty and thirty-two. Confinement was usually continued up to ninety-six hours, although the subject could obtain release at any time should he find the situation intolerable by pressing a button, although no continuation of the test was permitted once he had left the cubicle. The usual arrangements were made for providing food and toilet facilities.

As a result of the experiments a number of facts relating to conditions of sensory deprivation were found. About one out of five subjects used the release button before their time was up; and although they were forbidden to smoke they found to their surprise that they no longer wanted to do so. It was found that, using the body-sway test, suggestibility could be increased and the underestimation of time was a marked characteristic. Effects on thinking varied: in some cases it remained clear, but for most subjects connected thought became weaker the longer confinement was continued.

As regards physical effects, it was found that confinement had an undesirable effect on some simple motor tasks, although no effect on reaction time was observed. Sensitivity to pain was increased, and what was more unexpected was a loss of weight due to the fact that the subjects did not consume enough to prevent it.

Dr. Vernon's study is a clear and interesting exposition of the general effects of sensory deprivation under certain well-defined conditions. But what is now clear is that much more work will have to be done, including tests with less educated and with female subjects and with persons of widely differing age groups. It seems that man does not well endure such conditions, since they afford no variation in the few stimuli presented to him. Even the simplest stimulus is received with pleasure and becomes a subject for study. If the results of sensory deprivation are to be accepted, then the dependence of modern man on the external world and the limitations of his own selfsufficiency have been exemplified. E. J. Dingwall

\section{PARASITES OF FRESHWATER FISH}

Key to Parasites of Freshwater Fish of the U.S.S.R. Compiled by I. E. Bykhovskaya-Pavlovskaya et al. Translated from the Russian. Pp. viii +919. (Jerusalem : Israel Program for Scientific Translations; London: Oldbourne Press, 1964.) 180s.

KEY to Parasites of Freshwater Fish of the U.S.S.R. $K_{\text {was originally published in } 1962 \text {. The book contains }}$ keys to the identification of 1,211 species of parasites from freshwater fish of the U.S.S.R. The parasites belong to seven phyla and fifteen classes of invertebrates. The keys are constructed on a dichotomous pattern, and require comparisons of characters of the parasite to be made. A description of each species of parasite is given.

The Protozoa occupy 231 pages of the translation; the Coelenterata, 2 pages; the Platyhelminthes Monogenoidea, 207 pages; Cestoidea, 66 pages; Trematoda (Digenea), 104 pages; the Nemathelminthes Nematoda,
67 pages; Acanthocephala, 45 pages; the Annelida Hirudinea, 13 pages; the Mollusca, 4 pages; the Arthropoda Crustacea, 57 pages; and Arachnoidea, 5 pages. There is a twelve-page index of common and Latin names of the fish, followed by a thirty-nine-page list of parasites of the freshwater fish of the U.S.S.R., arranged under species of host. The bibliography gives references to 249 Russian and 116 foreign (non-Russian) publications. A list entitled "Basic Manuals, Keys and Papers on Fish Parasites" contains thirty titles, all by non-Russian authors.

The index of Latin names of the parasites is photographically reproduced from the original publication and occupies the final thirty-three pages of the book. Unfortunately, the page numbers of the original book are given, and although these are shown at the margins of the text of the translation, the index is inconvenient to use at first. Thus the text of p. 665 of the Russian original appears on pp. 784 and 785 of the translation.

According to the introduction, the book is for the use of persons of biological background who are not necessarily parasitologists. Each section commences with an introduction which describes the morphology, biology, phylogeny and epizootological significance of the parasites being considered. This is an excellent feature, but I am doubtful if a person inexperienced in the study of some of the groups of parasites would be able to find and correctly interpret some of the structures. It is strongly recommended that identifications made by inexperienced workers be referred to an expert for confirmation. This comment is not intended to condemn the selection of key characters, or the construction of the keys. It is a warning that identification is not necessarily an easy process, and that incorrect determinations can be easily made no matter how good the keys.

The descriptions given for each species of parasite are brief and to the point. The illustrations are largely from the world literature, although some are original. On the whole they are good, but some have suffered in quality owing to their manner of reproduction in the translation.

The book is a key to the parasites of the fishes of the U.S.S.R., and species not found in the U.S.S.R. are omitted. This is an obvious point, but, as the translation will be used outside the U.S.S.R., it is an important one. If the keys do not work for a parasite, it must be remembered that it may be a species not recorded from the U.S.S.R.

The translation from the Russian appears to be accurate. A comparison of the part of the book dealing with the class Cestoidea was made with a translation of the same part prepared by the Translations Section of the National Lending Library ${ }^{1}$. The comparison was favourable, as the two translations were identical in factual content and interpretation of the Russian original.

The editor and authors of the original publication are to be congratulated on the excellent compilation. As they point out in the foreword, the authors are under no illusion that the work is complete, or free from deficiencies. They invite critical remarks and supplementary material for incorporation in future editions. The translators should also be complimented on the production of the English version in the relatively short time since the appearance of the original.

While not everyone will agree with the taxonomic treatment given to some of the groups of parasites, this in no way affects the value of the book as a key-work. The book is highly recommended, and should be an invaluable aid to the identification of freshwater fish parasites. The keys were tested with a variety of parasites from several groups, and the correct identifications achieved.

JAMES C. ChuBB

${ }^{1}$ Dubinina, M. N., Class-Tapeworms. Translation of pp. 384-438 Opredelitel Parazitov Presnovodnich Rib S.S.S.R. Akad. Nauk S.S.S.R. Mosecw Lecember, 1964). 